\title{
PERAN MEDIASI PERSON-JOB FIT DAN JOB RESOURCES PADA JOB CRAFTING DAN WORK ENGAGEMENT
}

\author{
${ }^{1}$ Akbar Dirgantara Putra, ${ }^{2}$ Marynta Putri Pratama \\ Manajemen S1, Sekolah Tinggi Ilmu Ekonomi Putra Bangsa Kebumen \\ e-mail : akbar_dp@rocketmail.com
}

\begin{abstract}
This research is based on phenomena and supported by existing journal articles, so that researchers are interested in conducting research on the role of mediating person-job fit and job resources on job crafting and work engagement. The purpose of this study was to analyze and explain the influence between independent variables, mediating variables and dependent variables. The population of this research is employees of PT. Semesta Pelita Harapan with a sample of 32 people. The sampling technique used was purposive sampling. Methods of collecting data with questionnaires, interviews and literature. The respondent's attitude was measured by a 5-level Likert scale and the data obtained was processed with SmartPLS (Partial Least Square)) for Windows version 3.2.8. Data analysis used descriptive analysis, and statistical analysis (mediation). The results of the study show that job resources act as full mediation between the relationship between job crafting and work engagement. Likewise, the personjob fit variable also has a full mediating role between the relationship of job crafting and work engagement.
\end{abstract}

Keyword: work engagement, job crafting, job resources \& personjob fit

\begin{abstract}
Abstrak
Penelitian ini dilakukan berdasarkan fenomena dan didukung artikel jurnal yang ada, sehingga peneliti tertarik melakukan penelitian tentang peran mediasi person-job fit dan job resources pada job crafting dan work engagement. Tujuan penelitian ini adalah menganalisis dan menjelaskan pengaruh antara variabel independen, variabel mediasi dan variabel dependen. Populasi penelitian ini yaitu karyawan PT. Semesta Pelita Harapan dengan sampel sebanyak 32 orang. Teknik pengambilan sampel yang digunakan adalah purposive sampling. Metode pengumpulan data dengan kuesioner, wawancara dan studi pustaka. Sikap responden diukur dengan skala likert 5 tingkatan dan data yang diperoleh diolah dengan SmartPLS (Partial Least Square))for windows versi 3.2.8. Analisis data menggunakan analisis deskriptif, dan analisis statistik (mediasi). Hasil penelitian menunjukan bahwa job resources berperan sebagai pemediasi penuh (full mediation) antara hubungan job crafting dengan work engagement. Begitupula dengan variabel person-job fit juga memiliki peran pemediasi penuh antara hubungan job crafting dengan work engagement.
\end{abstract}

Kata Kunci: work engagement, job crafting, job resources \& person-job fit 


\section{PENDAHULUAN}

Sumber daya manusia adalah aset yang paling berharga bagi perusahaaan, karena tanpa mereka sebuah perusahaan tidak dapat menjalankan kegiatan operasionalnya. Sumber daya manusia yang diharapkan oleh perusahaanadalah mereka yang bisa danmau terikat terhadap pekerjaannya (work engagement). Seperti yang dikatakanSchaufeli et. al. (dalam Ayu, Maarif \& Sukmawati, 2017) bahwa work engagement diartikan sebagai kondisi mental yang positif, memberikan kepuasan yang berhubungan dengan pekerjaan yang diartikan dengan semangat (vigor), dedikasi (dedication) dan penghayatan (absorption). Para pekerja akan mengeluarkan segenap kemampuan mereka tanpa adanya sebuah paksaan karena mereka telah larut dalam pekerjaan yang mereka jalankan.

Dalam dunia bisnis, perusahaan yang lebih unggul adalah perusahaan yang memiliki karyawan dengan tingkat work engagement tinggi, salah satunnya adalah PT. Semesta Pelita Harapan. Perusahaan tersebut memiliki karyawan dengan mental dan energi yang kuat dalam menyelesaikan pekerjaannya dan tetap mempertahankan dengan segala upaya meskipun sedang dalam kondisi yang sulit seperti ketika mendapat penugasan di area pegunungan yang penuh batu cadas yang keras untuk dilubangi maupun area terpencil yang tidak dapat dijangkau dengan alat berat. Meskipun dalam kondisi sesulit demikian, para karyawan tetap bekerja dengan baik tanpa kehilangan konsentrasi dalam bekerja. Hal - hal tersebut adalah sebuah makna pekerjaan yang membuat mereka memiliki rasa bangga karena telah terlibat dalam pekerjaan tersebut serta dapat menyelesaikan tantangan dari pekerjaan yang ditugaskan oleh perusahaannya.Keadaan keadaan itulah yang menandakan kondisi psikologis positif yang mendukung pekerjaan mereka sehingga memberikan kinerja yang baik bagi perusahaan. 
PT. Semesta Pelita Harapan memiliki tujuan menjadi perusahaan yang selalu dapat dipercaya oleh mitranya,beberapa diantaranya adalah PT. PLN, PT. Tonggak Ampuh \& PT. Tjakrindomas.Untuk dapat mempertahankan kerjasamanya dengan mitra, perusahaan harus memberikan hasil kerja yang memuaskan yang berarti mereka harus tetap berkinerja baik. Menurut Albana (2018), untuk dapat meningkatkan kinerja karyawan dalam perusahaan, diperlukan rasa keterikatan (engage) terhadap pekerjaannya. Karena semakin tinggi work engagementyang dimiliki, semakin tinggi pula kinerja yang diberikan terhadap perusahaan.

Karyawan yang memiliki work engagement tinggi akan bekerja dengan penuh energi dan semangat, hal tersebutlah yang akan memajukan perusahaan dimasa mendatang. Sebaliknya, karyawan yang memiliki work engagement rendah dapat menurunkan mutu serta reputasi perusahaan (Palupi, 2015). Karyawan yang tidak engage adalah pusat masalah, karena mereka akan kehilangan komitmen dan motivasi (Aktouf dalam Diah, 2015). Dengan kata lain, karyawan akan kehilangan dorongan terhadap pekerjaannya. Oleh karena itu, work engagement menjadi perhatian penting dalam aspek Sumber Daya Manusia.

Work engagement dapat dibentuk dengan baik oleh banyak faktor salah satunya adalah dengan faktor job craftingkaryawan, karena memiliki pengaruh positif yang akan meningkatkan keterikatan kerja ketika tingkatjob craftingyang dimiliki tinggi (Azizah \& Ratnaningsih, 2018). Tims \& Bakker (dalam Fazriati \& Budiono, 2017) mendefinisikan job crafting sebagai pengubahan batasan- batasan, kondisi tugas pekerjaan, hubungan kerja dan arti dari pekerjaan.Pada PT. Semesta Pelita Harapan, para karyawan lapangan melakukan pengubahan pekerjaan yang ditugaskan oleh perusahaan berupa penambahan unit beton serta mengubah cara penyelesaiaan penegerjaan demi mengoptimalkan daya angkut truk \&waktu kerja mereka yang dirasa masih lebih. Dalam mendesain ulang aspek tugas tersebut, para karyawan melakukan diskusi dengan rekan - rekan kerja mereka agar pengerjaan penanaman tiang beton terkoordinir dengan baik tanpa adanya miskomunikasi antar rekan dalam tim. Semua itu mereka lakukan karena mereka telah mengubah cara pandang pekerjaan mereka lebih kepada pengabdian kepada masyarakat terutama mereka yang membutuhkan jaringan listrik.

Berdasarkan observasi yang dilakukan, peneliti menemukan bahwa karyawan PT. Semesta Pelita Harapan telah melalukan pengubahan batasanbatasan pekerjaan \& arti dari pekerjaan mereka, sebagai contoh adalah kebebasan penggeseran koordinat letak penanaman tiang beton selama masih dalam lingkup yang wajar atau tidak terlalu jauh dari koordinat asal. Hal ini adalah sebuah inisiatif para karyawan untuk mengoptimalkan pekerjaan yang mereka laksanakan. Seperti yang diungkapkan Roczniewska\& Bakker (2016) bahwa ciri utama job crafting adalah modifikasi tugas atau karakteristik pekerjaan atas inisiatif sendiri.

Tidak hanya dengan job crafting, work engagement dapat dipengaruhijuga olehjob resources,job resources akan meningkatkan tingkat work engagement karyawan karena faktor-faktornya dapat secara intrinsik memotivasi untuk memenuhi keinginan dasar karyawan atau memotivasi secara ektrinsik karena berkontribusi untuk pencapaian tujuan kerja (Deviyanti \&Sasono, 2015).Karyawan yang terikat dalam pekerjaan mereka akan lebih mencurahkan perhatiannya pada pekerjaan, namun tergantung pula dengan besarnya sumberdaya pekerjaan (job resources) yang tersedia. Salah satu contoh job resourcesyang ada pada PT. Semesta Pelita Harapan adalah hubungan baik antar pekerja yang ditunjukkan oleh sikap peduli mereka kepada rekan yang membutuhkan bantuan terutama dalam hal pekerjaan. Tidak hanyaitu, sumber daya pekerja menjadi penting bagi karyawan juga karena memberikan keleluasaan dan memberikan kesempatan untuk mengembangkan keahlian yang dimiliki dalam hal pekerjaan. 
Phonthatullah (2015) menyatakan bahwa dalam bekerja, karyawan yang memiliki work engagement sangat membutuhkan sumber daya ketika mereka bekerja. Sumber daya pekerjaan (job resources) menjadi semacam bantuan ketika mereka menghadapi tuntutan dan hambatan kerja. Job resources adalah aspek fisik, sosial, psikologis, atau organisasional dari pekerjaan yang mampu mengurangi tuntutan pekerjaan dalam kaitanya dengan pengorbanan psikologis (psycological cost) yang diberikan karyawan. Job resources juga memberikan pengaruh pada pencapaian tujuan. Selain itu, menstimulasi pengembangan dan pembelajaran (Ayu, Maarif \& Sukmawati, 2017).

Dalam membentuk sebuah keterikatan kerja yang baik faktor kesesuaian diri dengan pekerjaan (person-job fit) memiliki pengaruh yang besar (Hanum \& Logahan, 2013; Fazriati \& Budiono, 2017; Salin, 2018) karena ketika karyawan memiliki kesesuaian dengan pekerjaannya, mereka akan bekerja dengan segenap kemampuan yang dimiliki. Person-job fit adalah keadaan yang menggambarkan adanya kesesuaian atau kemampuan karyawan dengan tuntutan pekerjaan, kebutuhan individu dan apa yang dapat diberikan oleh pekerjaan itu terhadap karyawan (Cable \& DeRue, 2002). Pada karyawan lapangan PT. Semesta Pelita Harapan, peneliti mendapati banyak individu yang memiliki jasmani yang bugar serta memiliki keahlian sesuai dengan spesifikasi pekerjaan mereka.

Berdasarkan uraian tersebut serta dukungan penelitian- penelitian terdahulu,peneliti tertarik melakukan penelitian dengan judul "PERAN MEDIASI PERSONJOB FIT DAN JOB RESOURCES PADA JOB CRAFTING DAN WORK ENGAGEMENT".

\section{METODE}

Penelitian ini merupakan penelitian kuantitatif dengan metode yang digunakan adalah purposive sampling. Menurut Sugiyono (2010) purposive sampling adalah teknik untuk menentukan sampel penelitian dengan beberapa pertimbangan tertentu yang bertujuan agar data yang diperoleh nantinya bisa lebih representatif. Seperti yang dilakukan peneliti dalam penelitian ini karena menitikberatkan pada karyawan PT. Semesta Pelita Harapan yang bekerja di lapangan dengan jumlah 32 orang.

\section{HASIL DAN PEMBAHASAN \\ Hasil Uji Validitas dan Reliabilitas \\ Uji Validitas}

Hasil uji validitas pada penelitian ini menghasilkan nilai loading factor $>0,70$ dan bernilai positif. Sehingga, dapat disimpulkan bahwa item pernyataan diajukan dengan total 40 item adalah valid.

\section{Uji Reliabilitas}

Hasil uji reliabilitas pada penelitian ini menghasilkan nilai cronbach alpha \& composite reliability variabel independen dan dependen terkait > 0,60 serta nil AVE $>0,50$. Sehingga, dapat disimpulkan bahwa pemilihan variabel penelitian terbukti reliable dan dapat digunakan sebagai data pengukuran dalam penelitian.

\section{Koefisien determinasi}

Tabel I

Hasil Uji Koefisien Determinasi ( )

\begin{tabular}{|c|c|c|c|}
\hline No & Variabel & RSquare & $\begin{array}{l}R \text { Square } \\
\text { Adjusted }\end{array}$ \\
\hline 1 & $\begin{array}{l}\text { Work } \\
\text { engagement }\end{array}$ & 0,388 & 0,356 \\
\hline $\begin{array}{l}2 \\
3\end{array}$ & $\begin{array}{l}\text { Person-job fit } \\
\text { Job resources }\end{array}$ & $\begin{array}{l}0,308 \\
0,187\end{array}$ & $\begin{array}{l}0,294 \\
0,170\end{array}$ \\
\hline
\end{tabular}

Sumber: SmartPLS 3.2.8

Berdasarkan tabel diatas besarnya $\mathrm{R}$ Square adalah 0,$388 ; 0,308 \& 0,187$ hal ini berati $38,8 \%$ work engagement dapat dijelaskan oleh job crafting sedangkan sisanya $(100 \%-38,8 \%)=61,2 \%$ dijelaskan oleh faktor lain diluar model;30,8\%person-job fit dapat dijelaskan olehjob craftingsedangkan sisanya $(100 \%-30,8 \%)=69,2 \%$ dijelaskan oleh faktor lain diluar model dan $18,7 \%$ job resources dapat dijelaskan olehjob crafting. Sedangkan sisanya $(100 \%-18,7 \%)=81,7 \%$ dijelaskan oleh faktor lain diluar model. 
Uji Effect size

Tabel II

Hasil Uji Effect size( )

\begin{tabular}{|c|c|c|c|}
\hline No & Variabel & Square & Rating \\
\hline 1 & Job crafting-Work & 0,029 & Small \\
\hline & engagement & & \\
\hline 2 & Job crafting-Job resources & 0,368 & Large \\
\hline 3 & $\begin{array}{l}\text { Job resources-Work } \\
\text { engageme } \\
n t\end{array}$ & 0,277 & Medium \\
\hline 4 & Job crafting -Person-job fit & 0,794 & Large \\
\hline 5 & Person-job fit-Work & 0,435 & Medium \\
\hline
\end{tabular}

Sumber: SmartPLS 3.2.8

\section{Uji Hipotesis}

Tabel V

Path Coefficients direct effect

\begin{tabular}{|c|c|c|c|c|c|}
\hline Jalur & O & Mean & STDEV & $\begin{array}{c}T \\
\text { values }\end{array}$ & $\begin{array}{c}P \\
\text { Values }\end{array}$ \\
\hline $\begin{array}{l}\text { Job crafting -> } \\
\text { Work engagement }\end{array}$ & 0,462 & 0,503 & 0,226 & 2,045 & 0,007 \\
\hline $\begin{array}{l}\text { Job crafting - } \\
>\text { Job resources }\end{array}$ & 0,516 & 0,519 & 0,157 & 3,279 & 0,001 \\
\hline $\begin{array}{l}\text { Job resources -> } \\
\text { Work engagement }\end{array}$ & 0,587 & 0,611 & 0,102 & 5,748 & 0,000 \\
\hline $\begin{array}{l}\text { Job crafting } \\
>\text { Person-job fit }\end{array}$ & 0,642 & 0,654 & 0,145 & 4,569 & 0,000 \\
\hline $\begin{array}{l}\text { Person-job fit -> } \\
\text { Work engagement }\end{array}$ & 0,699 & 0,684 & 0,088 & 7,636 & 0,000 \\
\hline
\end{tabular}

Sumber: SmartPLS 3.2.8.
Berdasarkan data tersebut, sebagian prediktor variabel laten memiliki pengaruh yang menengah dan besar terkecuali prediktor job crafting - work engagement.

\section{Uji Predictive Relevance}

Tabel III

Hasil Uji Predictive relevance $\left(Q^{2}\right)$

\begin{tabular}{|c|c|c|c|}
\hline No & Variabel & QSquare & Status \\
\hline 1 & Work engagement & 0,307 & $\begin{array}{l}\text { Predictive } \\
\text { relevance }\end{array}$ \\
\hline 2 & Person-job Fit & 0,219 & $\begin{array}{l}\text { Predictive } \\
\text { relevance }\end{array}$ \\
\hline 3 & Job resouces & 0,142 & $\begin{array}{l}\text { Predictive } \\
\text { relevance }\end{array}$ \\
\hline
\end{tabular}

Sumber: SmartPLS 3.2.8

Berdasar data tersebut dapat disimpulkan bahwa semua variabel memiliki relevansi prediksi karena $>0$.

\section{Uji Goodness of Fit Index}

\begin{tabular}{cc} 
Tabel IV & Hasil Uji GoF \\
GoF & Rating \\
\hline Sumber: SmartPLS & $\frac{\text { Large }}{\text { S.4.2.8 }}$
\end{tabular}

Dari tabel tersebut menggambarkan bahwa tingkat kesesuaian model secara keseluruhan yang dihitung dari residual kuadrat dari model yang diprediksi dibandingkan dengan data yang sebenarnya adalah besar. Berdasarkan pengujian, dan GoF terlihat bahwa model yang dibentuk adalah robust sehingga pengujian hipotesa dapat dilakukan.
Hasil penelitian menunjukan bahwa terdapat pengaruh job craftingterhadap work engagement dengan hasil uji koefisien beta sebesar 0, 462 atau 46,2\% dengan $T$-values

2, $045>1,96$ dan $P$-values $0,007<0,050$ sehingga dapat dikatakan bahwa variabel job craftingmemiliki pengaruh positif yang signifikan terhadap work engagement sehingga diterima. Penelitian ini mendukung penelitian terdahulu yang dilakukan oleh Azizah \& Ratnaningsih (2018) yang hasil penelitiannya menunjukan bahwa job crafting berpengaruh secara positif dan signifikan terhadap work engagement.

Hasil penelitian menunjukan bahwa terdapat pengaruh job crafting terhadap job resourcesdengan hasil uji koefisien beta sebesar 0 , 516 atau $51,6 \%$ dengan $T$ -

values 3, $279>1,96$ dan $P$-values $0,001<0,050$ sehingga dapat dikatakan bahwa variabel job crafting memiliki pengaruh positif yang signifikan terhadap job resources sehingga diterima.Penelitian ini mendukung penelitian terdahulu yang dilakukan oleh Heuval, Demerouti \& Peeters(2015) yang hasil penelitiannya menunjukan bahwa job crafting berpengaruh secara positifdan signifikan terhadap job resource.

Hasil penelitian menunjukan bahwa terdapat pengaruh job resourcesterhadap work engagement dengan hasil uji hasiluji koefisien beta sebesar 0, 587 atau 58, 7\% dengan

$T$-values 5, $748>1,96$ dan $P$-values $0,000<0$, 050 sehingga dapat dikatakan bahwa variabel job resourcesmemiliki pengaruh positif yang signifikan 
terhadap

work

engagement

sehingga

diterima.Penelitian ini mendukung penelitian terdahulu yang dilakukan oleh Ayu, Maarif \& Sukmawati(2015) yang hasil penelitiannya menunjukan bahwa job resources berpengaruh secara positifdan signifikan terhadap work engagement.

Hasil penelitian menunjukan bahwa terdapat pengaruh job crafting terhadap person-job fitdengan hasil uji koefisien beta sebesar 0, 642 atau 64, 2\% dengan $T$ values 4, $569>1,96$ dan $P$-values $0,000<$ 0,050 sehingga dapat dikatakan bahwa variabel job crafting memiliki pengaruh positif yang signifikan terhadap Deviyanti \& Sasono(2015) yang hasil penelitiannya menunjukan bahwa job crafting berpengaruh secara positifdan signifikan terhadap person-job fit.

Hasil penelitian menunjukan bahwa terdapat pengaruh person-job fitterhadap work engagement dengan hasil uji koefisien beta sebesar 0, 669 atau 66, 9\% dengan $T$ values 7, $636>1,96$ dan $P$-values $0,000<$ 0,050 sehingga dapat dikatakan bahwa variabel person-job fitmemiliki pengaruh yang signifikan terhadap work engagement sehingga diterima.Penelitian ini mendukung penelitian terdahulu yang dilakukan oleh Fazriati \& Budiono(2017) yang hasil penelitiannya menunjukan bahwa person-job fit berpengaruh secara positifdan signifikan terhadap work engagement.

\section{Uji Mediasi}

Tabel VI

Path Coefficients Indirect Effect

\begin{tabular}{|c|c|c|c|c|}
\hline $\begin{array}{l}\text { Job crafting - } \\
\text { Person-iob fit }\end{array}$ & 0,665 & 0,662 & 0,129 & 5,171 \\
\hline $\begin{array}{l}\text { Job crafting -Job } \\
\text { resouces }\end{array}$ & 0,519 & 0,507 & 0,163 & 3,183 \\
\hline
\end{tabular}

Sumber: SmartPLS 3.2.8.

Berdasarkan tabel tersebut, dapat diketahui bahwa semua variabel independen memiliki pengaruh yang signifikan terhadap variabel dependen (work engagement) terkecuali variabel independen job crafting sehingga \& diterima.

\section{PENUTUP}

\section{Simpulan}

Berdasarkan hasil pengolahan data kuisioner tentang Job crafting terhadap Work engagement yang dimediasi oleh Person-job fit dan Job resources di PT. Semesta Pelita Harapan dengan 32 responden maka dapat diambil kesimpulan sebagai berikut :

1) Hasil penelitian ini menunjukan bahwa variabel job crafting berpengaruh positif dan signifikan terhadap work engagement pada karyawan lapangan PT. Semesta Pelita Harapa.

2) Hasil penelitian ini menunjukan bahwa variabel job crafting berpengaruh positif dan signifikan terhadap job resources pada karyawan lapangan PT. Semesta Pelita Harapan.

3) Hasil penelitian ini menunjukan bahwa variabel job resources berpengaruh positif dan signifikan terhadap work engagaement pada karyawan lapangan PT. Semesta Pelita Harapan.

4) Hasil penelitian ini menunjukan bahwa variabel job resources memediasi penuh pengaruh antara job crafting terhadap work engagement pada karyawan lapangan PT. Semesta Pelita Harapan.

5) Hasil penelitian ini menunjukan bahwa variabel job crafting berpengaruh positif dan signifikan terhadap person-job fit pada karyawan lapangan PT. Semesta Pelita Harapan.

6) Hasil penelitian ini menunjukan bahwa variabel personjob fit berpengaruh positif dan signifikan terhadap work

\begin{tabular}{|c|c|c|c|c|c|}
\hline Jalur & O & Mean & STDEV & $\begin{array}{l}T \\
\text { values }\end{array}$ & $\begin{array}{l}P \\
\text { Values }\end{array}$ \\
\hline Person-job fit- & 0,592 & 0,599 & 0,174 & 3,409 & 0,001 \\
\hline
\end{tabular}

engagaement pada karyawan lapangan PT. Semesta Pelita Harapan.

Work

$\begin{array}{llllll}\text { Job resouces - } & 0,413 & 0,397 & 0,163 & 2,527 & 0,015\end{array}$

$>$ Work

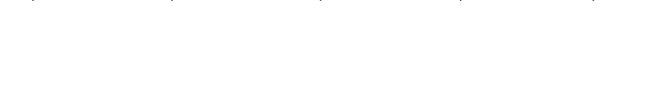

engagement

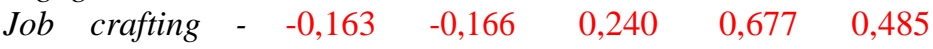

7) Hasil penelitian ini menunjukan bahwa variabel personjob fit memediasi penuh pengaruh antara job crafting terhadap work engagaement pada karyawan lapangan PT. Semesta Pelita Harapan. 


\section{Saran}

Berdasarkan hasil penelitian, pembahasan dan kesimpulan yang diperoleh, maka saran yang dapat diberikan penulis adalah sebagai berikut :

1) PT. Semesta Pelita Harapan sebaiknya mempertahankan tingkat job crafting karyawannya dengan cara tetap memberikan keleluasaan pengerjaan tugas selama masih dalam kondisi safety (aman).

2) PT. Semesta Pelita Harapan sebaiknya meingkatkan job resources dengan menambah intensitas hubungan yang baik dalam perusahaan dan menambah program pemberdayaan.

3) PT. Semesta Pelita Harapan sebaiknya mempertahankan person-job fit dengan tetap menempatkan karyawannya sesuai kemampuan yang mereka miliki dan minat yang mereka inginkan.

4) PT. Semesta Pelita Harapan juga sebaiknya mempertahankan work engagement yang tinggi pada karyawannya agar tetap tercipta pengerjaan proyek yang tepat waktu dan memuaskan mitra pada tiap tahunnya.

5) Untuk pngembangan penelitian selanjutnya, peneliti menyarankan untuk menambah/mengganti variabel lain yang mungkin dapat memediasi pengaruh variabel job crafting terhadap work engagement, serta penggantian locus penelitian.

\section{DAFTAR PUSTAKA}

Ayu, D. R., Maarif, M. S., \& Sukmawati, A. (2015). Pengaruh Job Demands, Job Resources dan Personal Resourcesterhadap Work Engagement. Jurnal Aplikasi Bisnis dan Manajemen (JABM), 1(1), 12.

Albana, H. (2018). Pengaruh Job Crafting terhadap Kinerja Karyawan yang Dimediasi oleh Work Engagement di PT. Terminal Teluk Lamong, Surabaya. Jurnal Ilmu Manajemen (JIM), 7(1).

Azizah, R., \& Ratnaningsih, I. Z. (2018). Hubungan antara Job Crafting dengan Keterikatan Kerja pada Karyawan Generasi Y di Kantor Pusat PT. Bank Bukopin, Tbk Jakarta. Empati, 7(2), 167- 173.

Bakker, A. B., Demerouti, E., \& Sanz-Vergel, A. I. (2014). Burnout and work engagement: The JD-R approach. Annu. Rev. Organ. Psychol. Organ. Behav., 1(1), 389-411.
Bimantri, P. (2015). Pengaruh job demands, personal resources, dan jenis kelamin terhadap work engagement.Skripsi Sarjana. Jakarta : Fakultas Psikologi UIN Syarif Hidayatullah.

Cable, D. M., \& DeRue, D. S. (2002). The convergent and discriminant validity of subjective fit perceptions.Journal of applied psychology, 87(5), 875.

Demerouti, E., Bakker, A. B., \& Gevers, J. M. (2015). Job crafting and extra-role behavior: The role of work engagement and flourishing. Journal of Vocational Behavior, 91, 87-96.

Deviyanti, A. D., \& Sasono, A. D. (2015). Pengaruh Sumber Daya Pekerjaan (Job Resources) dengan Keterikatan Kerja (Work Engagement) sebagai Mediator terhadap Perilaku Proaktif (Studi Pada Karyawan PT RGA International Indonesia). Jurnal Ilmu Manajemen MAGISTRA Vol, 1(1).

Fazriati, N. F. (2017). Pengaruh Job Crafting terhadap Work Engagement yang Dimediasi oleh Person Job Fit pada PT. Berlian Jasa Teminal Indonesia. Jurnal Ilmu Manajemen (JIM), 5(3).

Ghozali, Imam. 2009. Aplikasi Analisis Multivariet dengan program SPSS. Edisi keempat. Semarang: Universitas Diponegoro.

Ghozali, Imam. \& Latan, Hengky. 2015. Partial Least Square Konsep, Teknik dan Aplikasi menggunakan Program SmartPLS 3.0. Edisi 2. Semarang: Universitas Diponegoro.

Harju, L. K., Hakanen, J. J., \& Schaufeli, W. B. (2016). Can job crafting reduce job boredom and increase work engagement? A three-year cross-lagged panel study. Journal of Vocational Behavior, 95, 11-20.

Han, T. S., Chiang, H. H., McConville, D., \& Chiang, C.

L. (2015). A longitudinal investigation of personorganization fit, person-job fit, and contextual performance: The mediating role of psychological ownership. Human Performance, 28(5), 425-439.

Juliati, J., Purnamasari, Y., Anggraeni, R. N., Sulistari, S., Purnamasari, R., Tama, F. E. S., ... \& Tesalonik, O. (2015). Pengaruh Person Organization Fit dan Person Job Fitpada OCB. In Management Dynamic Conference [MADIC] (Vol. 1, No. 1).

Kooij, D. T., van Woerkom, M., Wilkenloh, J., Dorenbosch, L., \& Denissen, J. J. (2017). Job crafting towards strengths and interests: The effects 
of a job crafting intervention on person-job fit and the role of age. Journal of Applied Psychology, 102(6), 971.

Lu, C. Q., Wang, H. J., Lu, J. J., Du, D. Y., \& Bakker, A.

B. (2014). Does work engagement increase personjob fit? The role of job crafting and job insecurity. Journal of Vocational Behavior, 84(2), 142-152.

Nabila Hanum, P. R. I. T. A., \& Logahan, J. M. (2014). Analisis Pengaruh Person-Job Fit dan Person- Organization Fit terhadap Work Engangement Karyawan pada PT. Arvindo Ciptagemilang, Kantor Pusat(Doctoral dissertation, BINUS).

Noerant, S. O., \& Prihatsanti, U. (2018). Hubungan antara Iklim Organisasi dengan Work Engagement pada Anggota Sabhara Polda Jateng Semarang. Empati, 6(4), 354-361.

Petrou, P., Demerouti, E., Peeters, M. C., Schaufeli, W. B., \& Hetland, J. (2012). Crafting a job on a daily basis: Contextual correlates and the link to work engagement. Journal of Organizational Behavior, 33(8), 1120-1141.

Phonthatullah, F. (2015). Pengaruh spiritualitas di tempat kerja, sumber daya pekerjaan, dan job crafting terhadap work engagemen. Skripsi Sarjana. Jakarta : Fakultas Psikologi UIN Syarif Hidayatullah.

Putri, N. S., \& Setiawan, H. H. (2018). Pengaruh Job Embeddedness dan Work Engagement terhadap Turnover Intention Karyawan PT Surya Donasin(Cabang Subang). Skripsi Sarjana. Bandung : Fakultas Ekonomi dan Bisnis Unpas Bandung

Rahmawati, A. N. (2016). Hubungan Antara Work Engagement dan Work-Family Conflict yang Dimoderasi oleh Conscientiousness (Studi pada Karyawati di PT. Angkasa Pura I (Persero) Juanda Surabaya). Jurnal Ilmu Manajemen (JIM), 4(2).

Ringle, C. M., Wende, S., dan Becker, J.-M. 2015. "SmartPLS 3." Boenningstedt: SmartPLS GmbH, http://www.smartpls.com.

Roczniewska, M., \& Bakker, A. B. (2016). Who seeks job resources, and who avoids job demands? The link between dark personality traits and job crafting. The Journal of psychology, 150(8), 1026-1045.

Salim, Ukhti M. R. (2018). Pengaruh Motivasi Intrinsik dan Job Crafting terhadap Work Engagement dan Person-jo fit sebagai variabel mediasi. Skripsi Sarjana. Kebumen : Program Studi Manajemen STIE Putra bangsa.

Schaufeli, W. B., Salanova, M., González-Romá, V., \& Bakker, A. B. (2002). The measurement of engagement and burnout: A two sample confirmatory factor analytic approach. Journal of Happiness studies, 3(1), 71-92

Sekaran, Uma. 2011. Research Methode for Business. Edisi 1 dan 2. Jakarta: Salemba Empat. Siagian, D dan Sugiarto. 2006. Metode statistika. Jakarta: Gramedia Pustaka Utama.

Slemp, G. R., \& Vella-Brodrick, D. A. (2013). The Job Crafting Questionnaire: A new scale to measure the extent to which employees engage in job crafting. International Journal of Wellbeing, 3(2).

Solihin, M. Dan Ratmono, D. 2013. Analisis SEM-PLS dengan WarpPLS 3.0. Edisi . Yogyakarta: ANDI.

Sugiyono. 2010. Metode penelitian kuantitatif kualitatif dan R\&D. Bandung: Alfabeta.

Tims, M., Bakker, A. B., \& Derks, D. (2012). Development and validation of the job crafting scale. Journal of vocational behavior, 80(1), 173- 186.

Van Wingerden, J., Derks, D., \& Bakker, A. B. (2018). Facilitating interns' performance: The role of job resources, basic need satisfaction and work engagement.Career Development International, 23(4), 382-396.

Van den Heuvel, M., Demerouti, E., \& Peeters, M. C. (2015). The job crafting intervention: Effects on job resources, self-efficacy, and affective well-being. Journal of Occupational and Organizational Psychology, 88(3), 511-532.

Wrzesniewski, A., \& Dutton, J. E. (2001). Crafting a job: Revisioning employees as active crafters of their work. Academy of management review, 26(2), 179201. 